\title{
MODELLING OF HEAT PROCESSES FOR DATA TRANSMISSION EQUIPMENT FOR OPERATION AT HIGH TEMPERATURE
}

\author{
Janis Galins, Aigars Laizans, Ainars Galins \\ Latvia University of Life Sciences and Technologies, Latvia \\ janis.galins@1lu.lv, aigars.laizans@1lu.lv, ainars.galins@1lu.lv
}

\begin{abstract}
Modern automation processes are being improved. The use of autonomous robots in agriculture is increasing. Data collection requires the use of high-resolution cameras that produce very large amounts of data. The CPU emits a significant amount of heat when processing the resulting data. Consideration must be given to global warming, which has resulted in ambient temperatures in certain continents reaching critically high values, which could adversely affect the operation of electronic equipment. Active cooling solutions are known to work much more efficiently than passive cooling systems. For equipment designed for outdoor use, active cooling, due to its specific nature, poses significant inconvenience and risks, because the unit can overheat if the fan stops, or if the ventilation ducts or filters are blocked. The experiments used a Wi-Fi base station capable of data rates of up to $867 \mathrm{Mbps}$. The outside of the unit body can be warmed up to $70^{\circ} \mathrm{C}$ or more by exposure to solar radiation. In order for the data transmission components to operate efficiently and safely in the open air, it is necessary to ensure that the passive cooling system developed dissipates heat sufficiently into the environment. As a result of the study a curve was created, which shows how the warming temperature of the critical component varies with the ambient temperature. The maximum permissible ambient temperature values at which the unit can operate were determined. The obtained results will allow to evaluate the cooling efficiency of the design of the investigated $\mathrm{Wi}-\mathrm{Fi}$ device in extreme climatic conditions, which is especially relevant for devices used in high temperature climatic zones. Air and heat flow simulations represent how heat is dissipated inside and outside the unit.
\end{abstract}

Keywords: cooling system, heat transfer, modelling, convection, CFD.

\section{Introduction}

Most of Wi-Fi transmission equipment use passive cooling solutions, because they are more reliable in operation. Thermal interface materials, heat transfer bridges, spreaders and heatsinks are widely used [1]. Air convection should also be considered. The choice of the cooling solution depends on various conditions:

- amount of heat emitted;

- recommended operating temperatures of the components;

- ambient conditions (temperature, moisture, ultraviolet and infrared radiation, aggressive gases).

Often, the specific design of the data transmission equipment complicates the calculation of heat transfer, so preference is given to flow and heat transfer simulations, which allow temperature determination at any point in the $3 \mathrm{~d}$ model. There are three mechanisms responsible for heat transfer: conduction, convection, and radiation. In fluid regions Solidworks Flow Simulation solves the NavierStokes equations, which are formulations of mass, momentum and energy conservation laws. Heat conduction is governed by Fourier's law. Solidworks Flow Simulation includes 2 models for radiation between solid surfaces and in transparent solids:

1. Ray Tracing, also known as DTRM (Discrete Transfer Radiation Model);

2. Discrete Ordinates (or DO) [2-4].

The study uses thermography, experimental temperature measurements and Solidworks flow simulations to test the heat dissipation of data transmission equipment.The aim of the work is to determine the maximum ambient temperature up to which the equipment can safely operate.

\section{Materials and methods}

The study is about an outdoor Wi-Fi base station with a control board integrated into the antenna body. When performing the experimental measurements, the unit operated at $50 \%$ workload with data transmission of $\sim 400 \mathrm{Mbps}$. Electrical power varied depending on the data transmission rate, thus reaching the consumed electric power of $\sim 8 \mathrm{~W}$. Both experimental temperature measurements and simulations were performed. 
The heating components on the printed circuit board (PCB) were identified using a thermal imager Testo 868. The thermography camera has an accuracy of $\pm 2{ }^{\circ} \mathrm{C}, \pm 2 \%$ of the measurement value. Emissivity can be set from 0.01 to 1 [5]. The top and bottom heatsinks were removed from PCB before taking the thermographic image. The Wi-Fi unit was operated for a short time to prevent overheating.

Experimental temperature measurements were made using a data logger PicoLog TC-08 with 8 type $\mathrm{K}$ thermocouples. Temperature measurements were taken every second with accuracy of $\pm 1.5^{\circ} \mathrm{C}[6]$.

Network Cable TesterNF-488was used to measure the consumed electrical power, calibrated by a Fluke $87 \mathrm{v}$ multimeter.

Computational fluid dynamics (CFD) and heat transfer simulations were performed in the Solidworks software. The simulation model was developed based on the experimental temperature measurements, solid materials and environmental conditions. Only conduction and convection without radiation were used for simulated heat transfer. The structure of the simulation model is shown in Fig. 1.

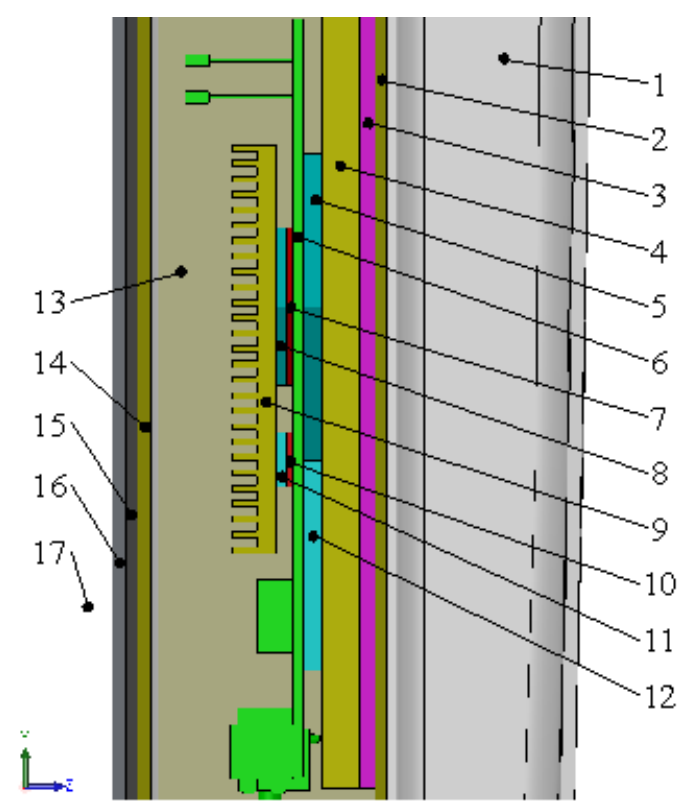

Fig. 1. Structure of the simulation model: 1 - ABS plastic shell; 2 - aluminium sheet; 3 - MS polymer; 4 - solid bottom heatsink; 5 - bottom thermal pad forIPQ4019 CPU; 6 - printed circuit

board; 7 - IPQ4019 CPU; 8 - top thermal pad for IPQ4019 CPU; 9 - top heatsink with fins;

10 - QCA9886 chipset; 11 - top thermal pad for QCA9886 chipset; 12 - bottom thermal pad for QCA9886 chipset and resistors; 13 - electromagnetic shield strip;

14 - aluminium sheet; 15 - gasket; 16 - cover; 17 - ambient air

The ambient air with the temperature of $25^{\circ} \mathrm{C}$ is around the unit. Passive cooling solutions with thermal pads and heatsinks were used to dissipate the heat into the environment. Possible problems can be caused by the air entrapped in the housing, therefore, convection was also studied.

Input data for CFD and heat transfer simulations were selected according to the model equipment and environmental conditions as shown in Table 1.

Input data for CFD and heat transfer simulations

Table 1

\begin{tabular}{|l|c|c|}
\hline \multicolumn{1}{|c|}{ Parameter } & Value & Unit \\
\hline Gravity in $y$ axis direction & -9.81 & $\mathrm{~m} \cdot \mathrm{s}^{-2}$ \\
\hline Atmospheric pressure & 101325 & $\mathrm{~Pa}$ \\
\hline Ambient temperature & 25 & ${ }^{\circ} \mathrm{C}$ \\
\hline Heat generation rate for semiconductors and resistors & 2.7 & $\mathrm{~W}$ \\
\hline Fluid type & \multicolumn{2}{|c|}{ Air } \\
\hline
\end{tabular}


The results of the simulations are significantly influenced by the thermal conductivity of the solid materials. The selected solid materials are shown in Table 2 .

Solid materials used for CFD and heat transfer simulations

\begin{tabular}{|c|c|c|c|}
\hline Part & Size, mm & Material & $\begin{array}{c}\text { Thermal } \\
\text { conductivity, } \\
\mathbf{W} \cdot(\mathbf{m} \cdot \mathbf{K})^{-1}[7]\end{array}$ \\
\hline IPQ4019 CPU & $18 \times 18 \times 1$ & \multirow{3}{*}{ Silicon } & \multirow{3}{*}{$\begin{array}{l}\sim 150 \text { (depends on } \\
\text { temperature) }\end{array}$} \\
\hline QCA9886 chipset & $9 \times 9 \times 1$ & & \\
\hline Resistor & $2 \times 2 \times 1$ & & \\
\hline Top thermal pad for large CPU & $18 \times 18 \times 3$ & \multirow{4}{*}{ Silicone } & \multirow{4}{*}{2} \\
\hline Top thermal pad for small CPU & $9 \times 9 \times 3$ & & \\
\hline Bottom thermal pad for large CPU & $35 \times 35 \times 3$ & & \\
\hline $\begin{array}{l}\text { Bottom thermal pad for small CPU } \\
\text { and resistors }\end{array}$ & $35 \times 50 \times 3$ & & \\
\hline Printed circuit board (PCB) & $144 \times 122 \times 1.7$ & Laminate FR4 & 0.3 \\
\hline Shell & $\begin{array}{l}290 \times 619 \times 73(\text { wall } \\
\text { thickness } 2 \mathrm{~mm})\end{array}$ & ABS plastic & 0.2 \\
\hline Top heatsink with fins & $140 \times 66 x 7$ & \multirow{5}{*}{ Aluminium } & \multirow{5}{*}{$\begin{array}{l}\text { 237 (depends on } \\
\text { temperature) }\end{array}$} \\
\hline Solid bottom heatsink & $145 \times 154 \times 6$ & & \\
\hline Sheet & $286 \times 615 \times 2$ & & \\
\hline Cover & $186 \times 320 \times 2$ & & \\
\hline Electromagnetic shield strip & $400 \times 35 \times 1$ & & \\
\hline Gasket & $\begin{array}{l}\text { 186x320x2 (inner } \\
\text { size } 160 \times 295)\end{array}$ & Neoprene & 0.05 \\
\hline
\end{tabular}

For air, silicon and aluminium curves were used, in which the thermal conductivity varies with temperature.

\section{Results and discussion}

The thermography camera helped identify the heating components on PCB. It was necessary to remove the heatsinks to see where the heat was coming from, thus putting the board at risk of overheating. The temperature range selected for the thermographic image is 24 to $58^{\circ} \mathrm{C}$ as shown in Fig. 2.

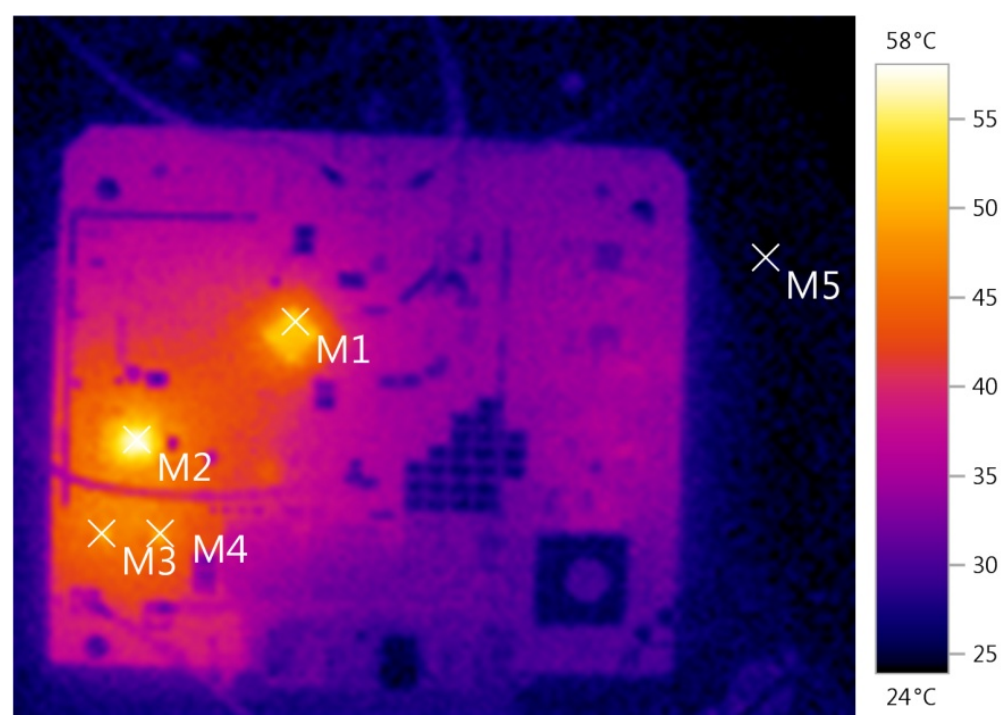

Fig. 2. Thermographic image of PCB without heatsinks

The thermography picture shows that a significant amount of heat is released by the Qualcomm Atheros IPQ4019CPU and Qualcomm Atheros QCA9886 chipset. The CPU supports the temperature 
range of $0{ }^{\circ} \mathrm{C}$ to $+110^{\circ} \mathrm{C}$ [8]. QCA9886 chipset supports $2 \mathrm{~T} 2 \mathrm{R}(2 \times 2)$ technology, which runs up to $867 \mathrm{Mbps}$. Desired operating temperature of chipset is $0^{\circ} \mathrm{C}$ to $+85^{\circ} \mathrm{C}[9]$. When the data transmission is turned on, two resistors begin to emit heat. The temperature points of thermography are shown in Table 3.

Table 3

Temperature points of thermography

\begin{tabular}{|c|c|c|c|c|}
\hline No & Location & Temperature, ${ }^{\mathbf{0}} \mathbf{C}$ & Emissivity & Reflected temperature, ${ }^{\mathbf{}} \mathbf{C}$ \\
\hline M1 & IPQ4019 CPU & 51.6 & & \\
\cline { 1 - 2 } M2 & QCA9886 chipset & 57.3 & \multirow{2}{*}{0.95} & 24 \\
\hline M3 & Resistor No1 & 48.5 & & \\
\hline M4 & Resistor No2 & 48.6 & \\
\hline M5 & Ambient temperature & 24.1 & & \\
\hline
\end{tabular}

Thermography pictures were taken without overheating of components above the recommended operating temperatures. The use of thermography to determine the maximum surface temperature is effectively used in other studies, indicating that thermography measurements are more accurate than thermocouple applications [10]. The thermographic image cannot be used, if the heating components are covered with the heatsink and are not directly visible when the unit is fully assembled.

CFD and heat transfer simulations were performed until the system reached a steady-state. When investigating the air convection inside the enclosure, it is decided to make modifications to the design of the electromagnetic shield as shown in Fig. 3.

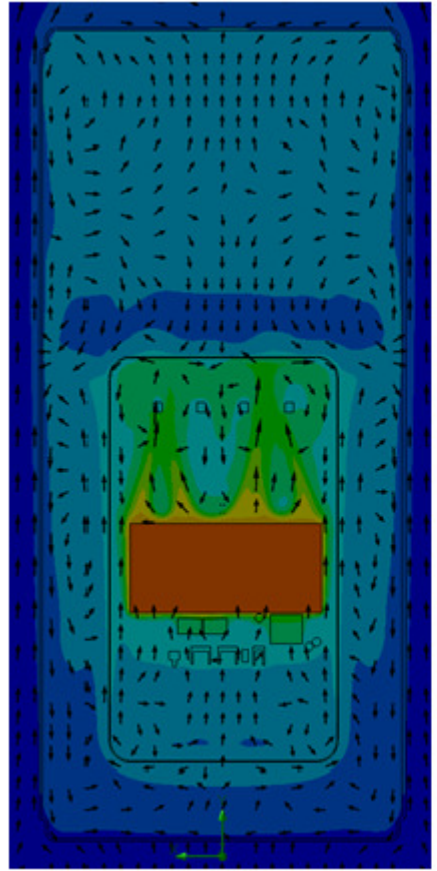

a)

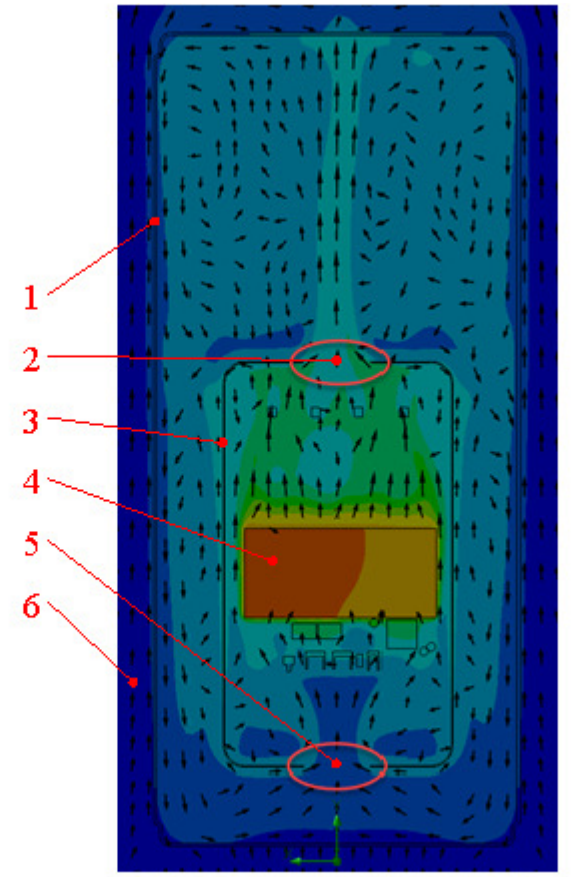

b)

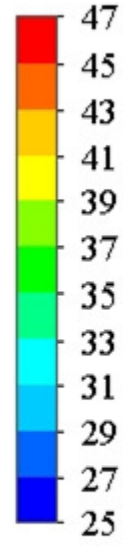

Temperature $\left[{ }^{\circ} \mathrm{C}\right]$

Fig. 3.Airflow trajectory and temperature: $\mathrm{a}$ - before electromagnetic shield modification; $\mathrm{b}$ - after electromagnetic shield modification; 1 - ABS plastic shell; 2 - top hole in electromagnetic shield; 3 - electromagnetic shield; 4 - top heatsink; 5 - bottom hole in electromagnetic shield; 6 - ambient air

To increase the efficiency of convection inside the housing, it was decided to cut holes in the top and bottom of the electromagnetic shield. Modification of the design of the electromagnetic shield increased the convection efficiency of the trapped air, thereby reducing the maximum processor heat up temperature by about $1{ }^{\circ} \mathrm{C}$.

Experimental temperature measurements were made until the system reached a steady-state. Thermocouples were placedin different locations inside the unit, as well as measuring the ambient temperature. The resulting dynamic heating curves are shown in Fig. 4. 


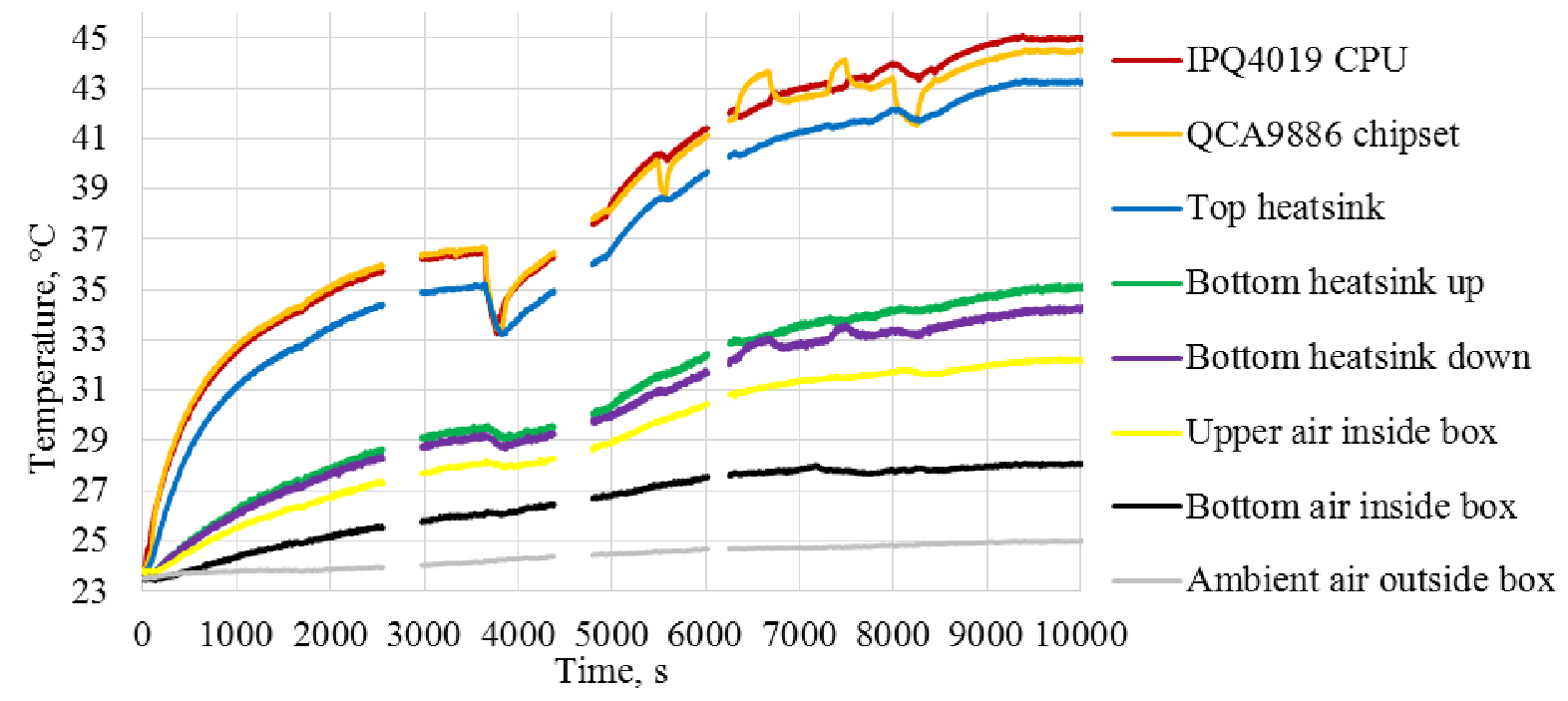

Fig. 4. Experimental temperature measurements using thermocouples

The data flow fluctuated, there were interruptions, but it eventually reached $\sim 400 \mathrm{Mbps}$. The IPQ4019 CPU reached maximum temperature of $45^{\circ} \mathrm{C}$, but QCA9886 chipsetreached maximum temperature of $44.5^{\circ} \mathrm{C}$. After $3650 \mathrm{~s}$, it is shown that the unit is temporarily shut down according to the temperature drop for all 7 thermocouples inside the unit. When the unit is turned on again, the curves continue to increase. The graph shows that the QCA9886 chipset starts to emit more heat by turning on the data flow. The temperature on the chipset drops when the data is interrupted. After 8050s, it is shown that data flow is interrupted and the temperature of QCA9886 chipset drops below the temperature of top heatsink. This can be explained by the fact that the top heatsink is cooled by convection and the bottom heatsink by conduction and convection. This leads to consider that the bottom heatsink took away more heat than the top. Two thermocouples were placed on the bottom heatsink: one higher and another lower. The air temperature was measured at the upper part and bottom inside the housing. When the system reached steady state, the upper air reached temperature of $32.2^{\circ} \mathrm{C}$ and bottom air $28.1^{\circ} \mathrm{C}$, thus convection of air is actuate by temperature difference of $4.1{ }^{\circ} \mathrm{C}$ due to density difference of air. The ambient temperature slowly increased and reached its maximum of $25^{\circ} \mathrm{C}$.

Simulation data were compared with experimental data. The developed simulation model corresponds to experimental temperature measurements by thermocouples as shown in Fig. 5 .

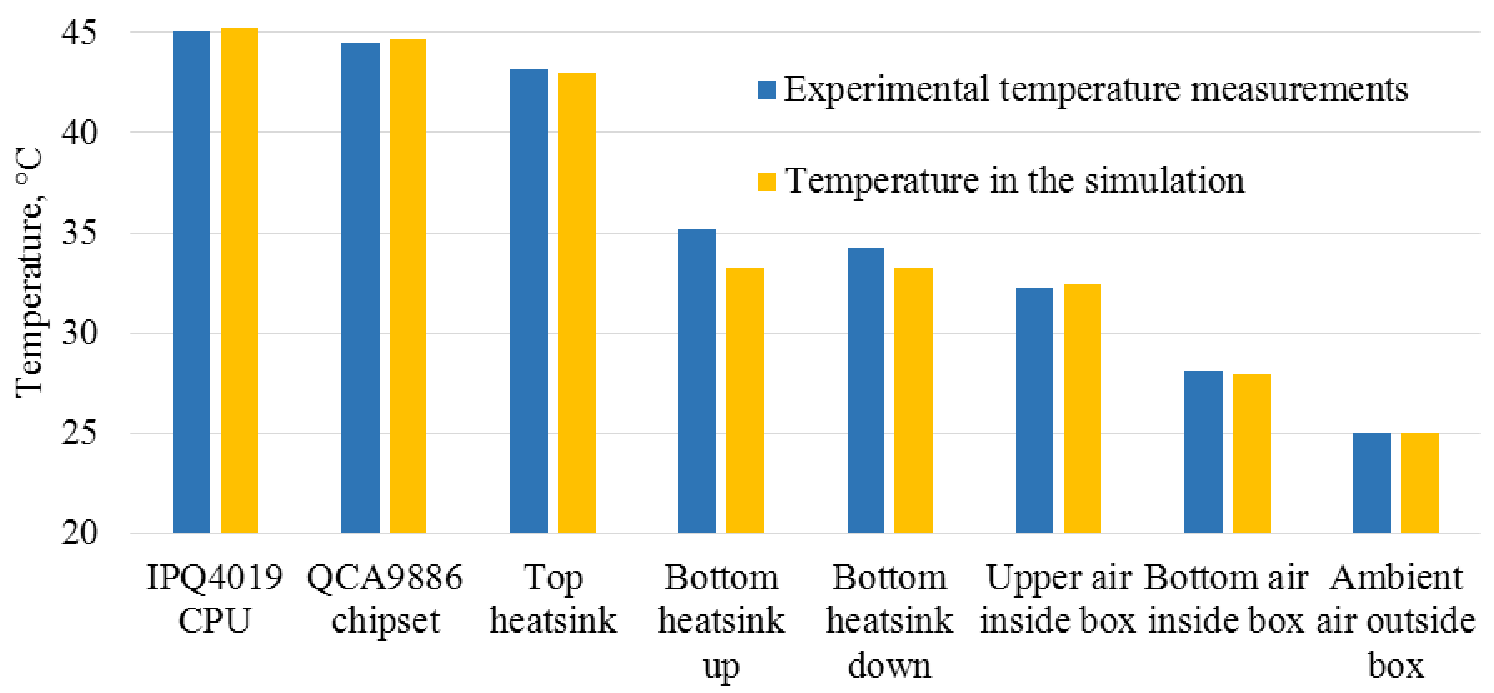

Fig. 5. Simulation and experimental measurement heating temperature comparison 
Most of the simulation temperatures showed very accurate accordance with the experimental measurements. The biggest difference in temperature was caused by the bottom heatsink where the temperature deviation was 1.0 to $1.8^{\circ} \mathrm{C}$. Using the simulation model, it was determined that the heat loss of unit was $2.7 \mathrm{~W}$, which means that the unit operates at $66 \%$ efficiency, because the consumed electric power was $8 \mathrm{~W}$. The simulation model can be used to obtain the temperature distribution of the CPU as shown in Fig. 6.
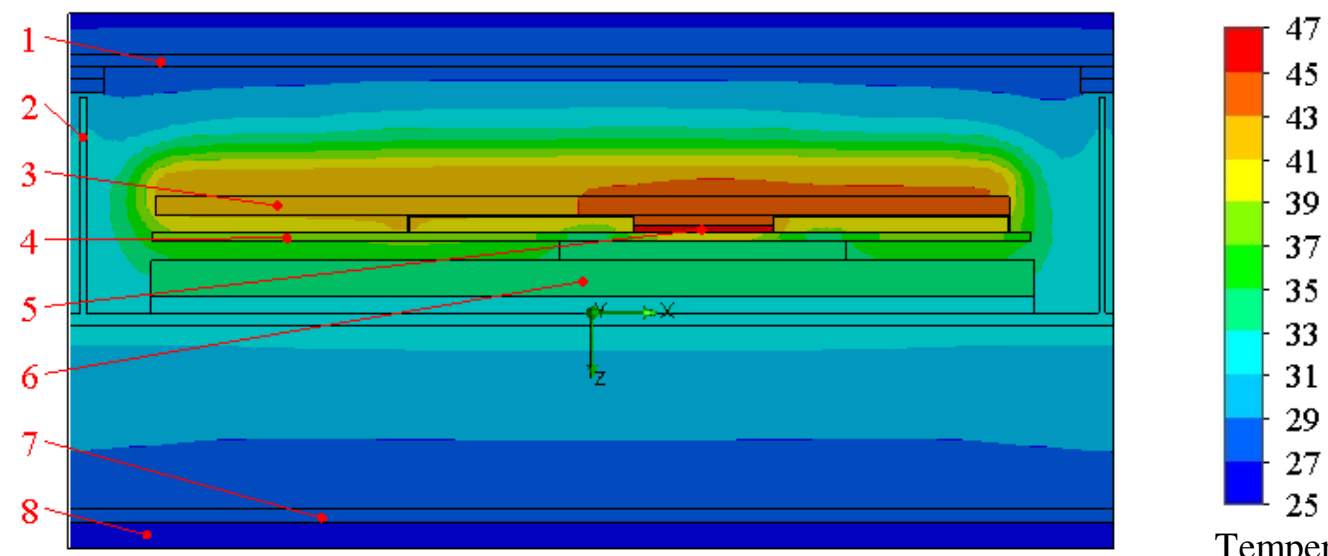

Temperature, ${ }^{\circ} \mathrm{C}$

Fig. 6. Temperature distribution of IPQ4019 CPU: 1 -cover; 2 - electromagnetic shield strip; 3 - top heatsink with fins; 4 - printed circuit board; 5 - IPQ4019 CPU; 6 - solid bottom heatsink; 7 - ABSplastic shell; 8 - ambient air

The temperature distribution shows that the top heatsink reaches much higher temperature than bottom heatsink. The heat flux through the top heatsink is also more intense than the bottom one as shown in Fig. 7.
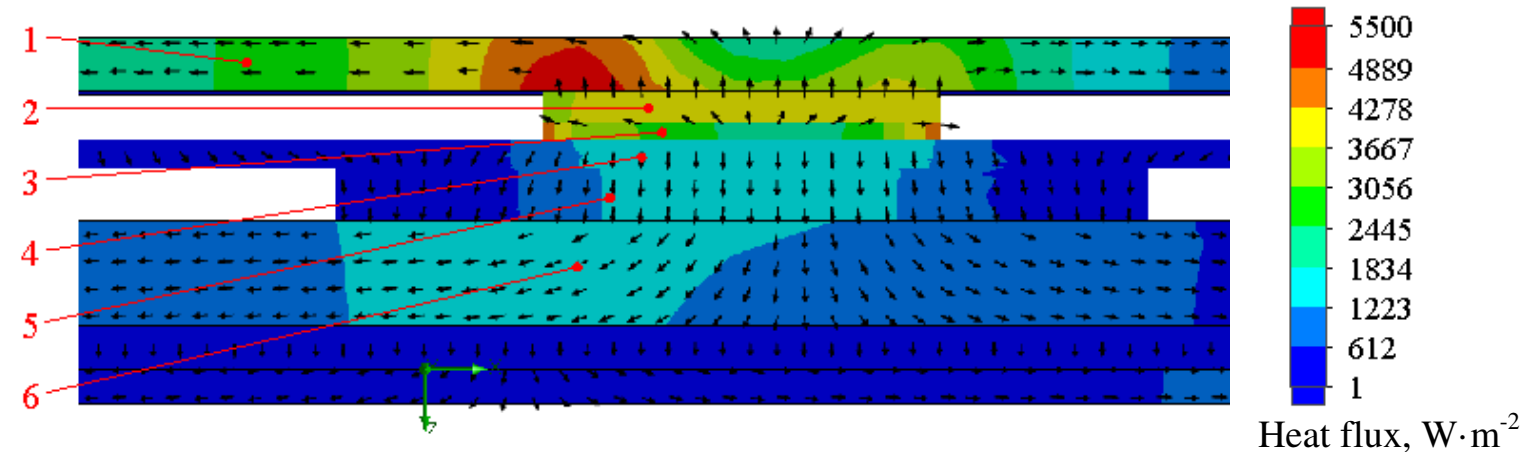

Fig. 7. Heat flux ofIPQ4019 CPU: 1 - top heatsink with fins; 2 - top thermal pad for IPQ4019 CPU; 3 - IPQ4019 CPU; 4 - printed circuit board; 5 - bottom thermal pad forIPQ4019 CPU; 6 - solid bottom heatsink

The heat flux is significantly affected by the printed circuit board, which has reduced the efficiency of the conductive cooling solution using bottom heatsink. The results of the simulations show that $1.5 \mathrm{~W}$ of heat transfer rate are passed through the thermal pads to the top heatsink and $1.2 \mathrm{~W}$ to the bottom heatsink. The conductive heat transfer efficiency to the bottom heatsink was improved by using larger size thermal pads.

Using the simulation model, a curve was created that shows how the maximum temperature of the CPU, chipset and heatsinks changes with the ambient temperature as shown in Fig. 8. The maximum ambient temperature at which the unit can safely operate is $65^{\circ} \mathrm{C}$, thus not exceeding the manufacturer's recommended QCA9886 chipset max permissible operating temperature of $85^{\circ} \mathrm{C}$. For the Wi-Fi base station to be able to operate at higher ambient temperatures, it would be necessary to increase the size of the top heatsink, because its efficiency is higher than the bottom heatsink.

Additional experimental measurements should be performed to determine how the heat loss of the unit changes as the processor temperature increases. Results may vary. 


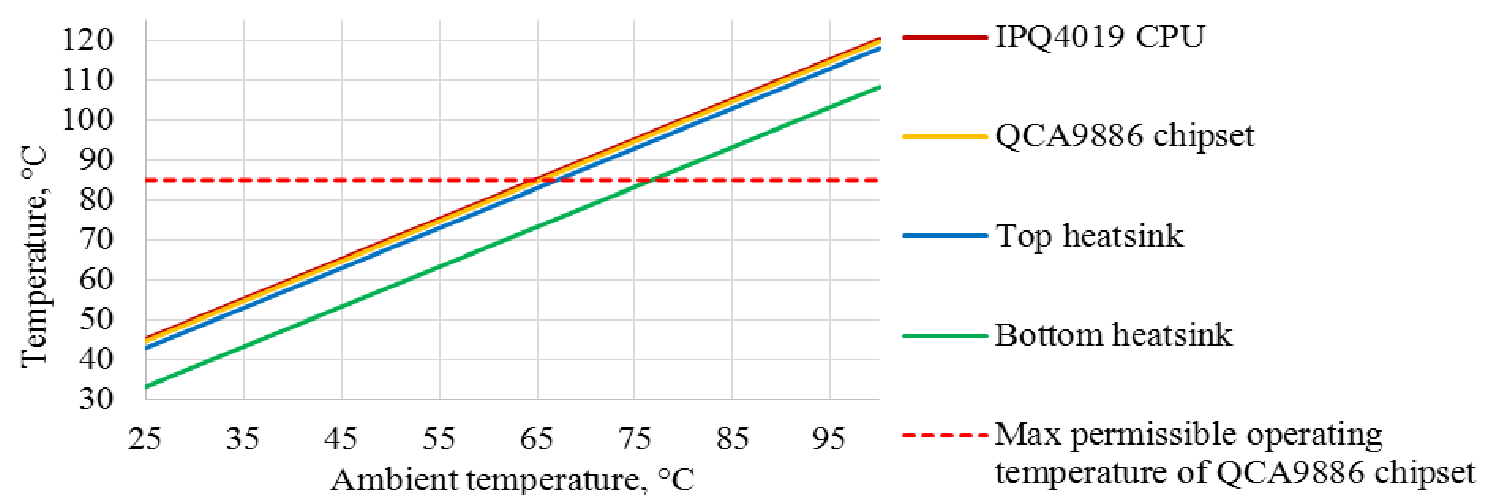

Fig. 8. Simulated component temperature dependence on ambient temperature

For other ambient temperature ranges, the resulting curve could show different results, because the air density and dynamic viscosity curves are not linear depending on temperature.

\section{Conclusions}

1. With $50 \%$ workload at the ambient temperature of $25^{\circ} \mathrm{C}$ the IPQ4019 CPU reached the maximum temperature of $45^{\circ} \mathrm{C}$, but QCA9886 chipset reached maximum temperature of $44.5^{\circ} \mathrm{C}$.

2. Modification of the design of the electromagnetic shield increased the convection efficiency of the trapped air, thereby reducing the maximum processor heat up the temperature by about $1^{\circ} \mathrm{C}$.

3. Most of the simulation temperatures showed very accurate accordance with the experimental measurements. The biggest difference in temperature was caused by the bottom heatsink, where the temperature deviation was 1.0 to $1.8^{\circ} \mathrm{C}$.

4. Using the simulation model, it was determined that the heat loss of the unit was $2.7 \mathrm{~W}$, which means that the unit operates at $66 \%$ efficiency, because the consumed electric power was $8 \mathrm{~W}$.

5. The results of the simulations show that $1.5 \mathrm{~W}$ of heat transfer rate are passed through the thermal pads to the top heatsink and $1.2 \mathrm{~W}$ to the bottom heatsink.

6. The maximum ambient temperature, at which the investigated Wi-Fi base station can safely operate, is $65^{\circ} \mathrm{C}$.

\section{Acknowledgements}

This work has been supported by the European Regional Development Fund within Project "Development of a Sustainable Heating Solution for the Salon of the Public Electric Transport", project identification number 1.1.1.1/18/A/168.

\section{References}

[1] Galins J., Laizans A., Galins A. Review of cooling solutions for compact electronic devices.Research for Rural Development, vol. 1, 2019, pp. 201-208.

[2] VyazovkinS.Thermal analysis.Analytical Chemistry, vol. 76, 2004, pp. 3299-3312.

[3] SolidWorks Corp. Electrical Analogy of Heat Conduction. [online] [10.09.2019]. Available at: https://help.solidworks.com/2018/english/SolidWorks/cworks/c_Electrical_Analogy_of_Heat_Co nduction.htm.

[4] Sobachkin A., DumnovG. Numerical Basis of CAD-Embedded CFD. NAFEMS World Congress, 2013, pp. 1-20.

[5] Testo SE \& Co. Data Sheet Testo 868,2020, p. 4.

[6] Pico Technology. Thermocouple tolerances. [online] [10.09.2019]. Available at: https://www.picotech.com/library/data-loggers/thermocouple-tolerances.

[7] SolidWorks Corporation, 2017, Solidworks.

[8] CODICO GmbH. Impulse, 2017, pp. 1-40.

[9] Qualcomm Technologies. QCA9886 SoC. [online] [10.09.2019]. Available at: https://www.qualcomm.com/products/qca9886.

[10] Rani M. F. H., Razlan Z. M., Shahriman A. B. etc. Comparative study of surface temperature of lithium-ion polymer cells at different discharging rates by infrared thermography and thermocouple. International Journal of Heat and Mass Transfer, vol. 153,2020, 1195 p. 